\title{
Surface-based molecular self-assembly: Langmuir-Blodgett films of amphiphilic Ln(III) complexes
}

\author{
Dominic J. Wales and Jonathan A. Kitchen*
}

\begin{abstract}
The unique photophysical properties of the Ln(III) series has led to significant research efforts being directed towards their application in sensors. However, for "real-life" applications, these sensors should ideally be immobilised onto surfaces without loss of function. The Langmuir-Blodgett (LB) technique offers a promising method in which to achieve such immobilisation. This mini-review focuses on synthetic strategies for film formation, the effect that film formation has on the physical properties of the Ln(III) amphiphile, and concludes with examples of Ln(III) LB films being used as sensors.
\end{abstract}

Keywords: Lanthanides, Langmuir, Langmuir-Blodgett, Surface, Sensors, Self-assembly, Amphiphilic, Luminescence, $\operatorname{Ln}(I I I)$

\section{Background}

The construction of lanthanide-based functional nanostructures is an active area of research. Trivalent lanthanide ions have readily manipulated coordination environments and interesting photophysical properties (e.g. sharp, long-lived emission at long wavelengths) making them particularly useful in molecular recognition and sensing [1-5]. The majority of studies have been carried out in solution, however to progress towards practical, robust and commercialised sensing applications (e.g. personal sensors or medical devices) these complexes should ideally be on a surface. As such there has been significant effort directed towards functionalising Ln(III) complexes with groups for surface attachment, including the formation of amphiphilic Ln(III) systems for Langmuir-Blodgett (LB) deposition.

The Langmuir-Blodgett technique [6] involves the self-assembly of amphiphilic molecules into an ordered mono-layer (Langmuir film) at an interface (usually air/ water) and subsequent transfer (via vertical deposition) of the self-assembled mono-layer onto a solid substrate

\footnotetext{
*Correspondence: J.A.Kitchen@soton.ac.uk Chemistry, University of Southampton, Southampton, Hampshire SO17 1BJ, UK
} 


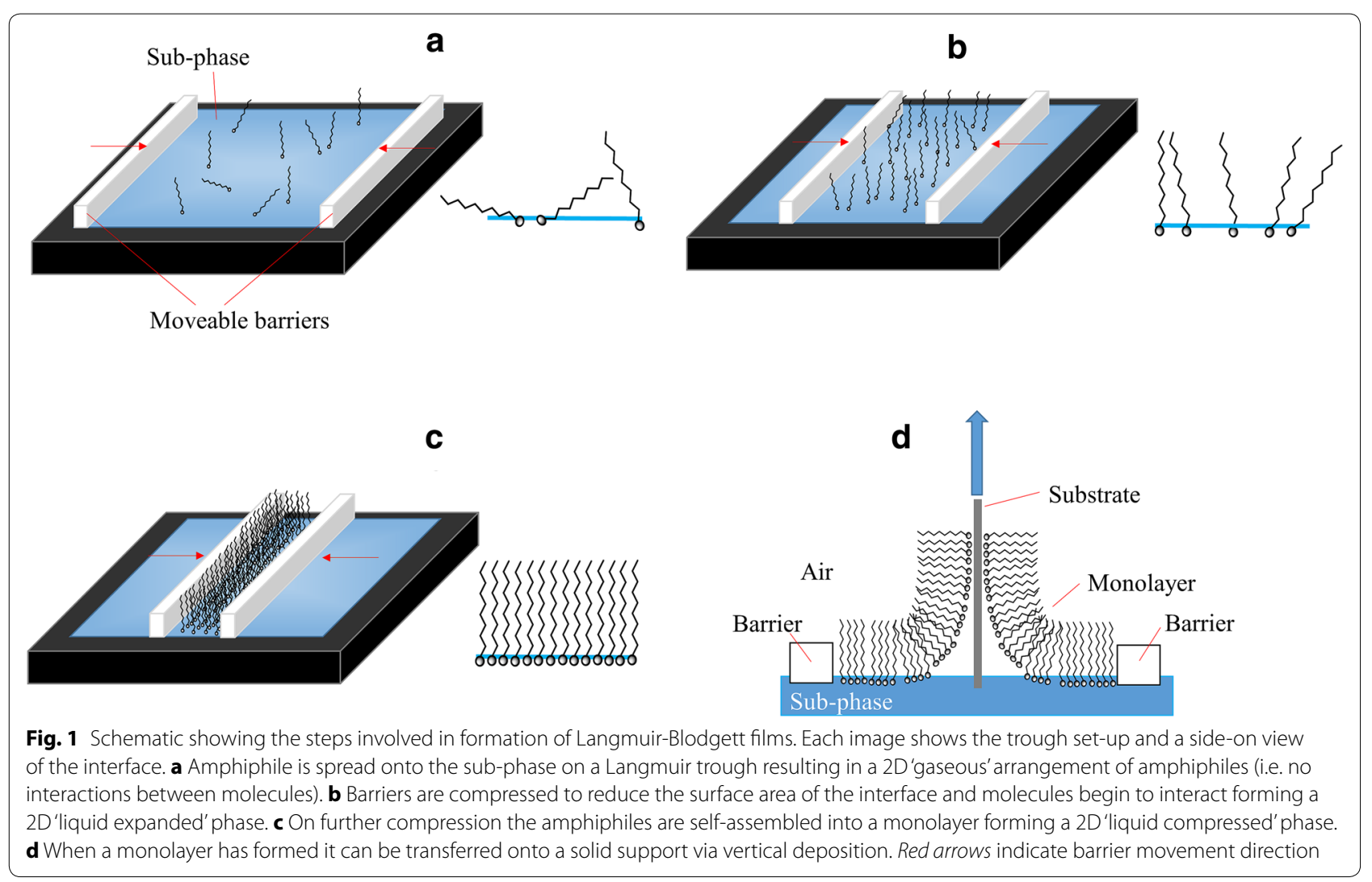

at the air water interface. The last example (which will not be discussed in this review due to space limitations) involves ion-pair systems where ionic Ln(III) complexes contain amphiphilic counter-ions (e.g. anionic or cationic surfactants outside of the $\operatorname{Ln}($ III) coordination sphere) [7, 8]. Again, due to the need for brevity, this review does not discuss the work on Langmuir-Blodgett films of Ln(III) bisphthalocyanines complexes, as this body of work has been thoroughly reviewed by Rodríguez-Mendez in 2009 and, to the best of our knowledge, there have been no reports of such systems since then [9].

Many of the initial studies in this field focused solely on the film forming abilities of $\operatorname{Ln}($ III) systems utilising the in situ approach. In these studies, fatty acids and fatty acid phosphate esters (Fig. 3) were deposited onto aqueous sub-phases containing $\operatorname{Ln}($ III) cations. These 'preliminary' studies have been pivotal to the further development of more advanced Ln(III) based functional materials, despite these initial systems not being luminescent. They have given information pertaining to design requirements for developing ligands (e.g. chain length), deposition conditions (e.g. expected isotherms) and characterisation methods for LB films. Some notable examples of in situ film formation include those of Linden and Rosenholm who prepared $\mathrm{Tb}(\mathrm{III})$ containing Langmuir films of simple long chain acids 1-4 [10] and Chunbo and co-workers who characterised striped domain $\mathrm{Eu}(\mathrm{III})$ containing LB films of 5 on mica using AFM [11]. The previous ligands were not ideal for $\operatorname{Ln}($ III) sensitisation, therefore Neveshkin and co-workers replaced the acid groups with larger, more complex chromophore containing calix[4] resorcinarene derivatives 6-8 (Fig. 4) to form Langmuir films on $\mathrm{Ln}$ (III) containing sub-phases [12].

\section{Effect of film formation on Ln(III) emission}

With sensing applications in mind, it is important to determine what effects (if any) the arrangement of $\operatorname{Ln}(\mathrm{III})$ ions in an ordered LB film has on the physical properties (i.e. emission properties) of the complex. The LB technique results in high local concentrations of amphiphiles in close proximity to a surface, therefore for $\operatorname{Ln}$ (III) containing films the biggest concern, especially if they are to be used as a sensor, is quenching of emission. A small number of studies have been carried out that investigated how film formation effected emission properties of the $\mathrm{Ln}$ (III) ions within the film.

Lemmetyinen and co-workers conducted timeresolved studies into the mechanism of the energy transfer from ligand 9 (Fig. 5) to $\mathrm{Eu}(\mathrm{III})$ or $\mathrm{Tb}$ (III) ions in $\mathrm{LB}$ films [13]. The energy transfer between 9 and $\mathrm{Eu}(\mathrm{III})$ 


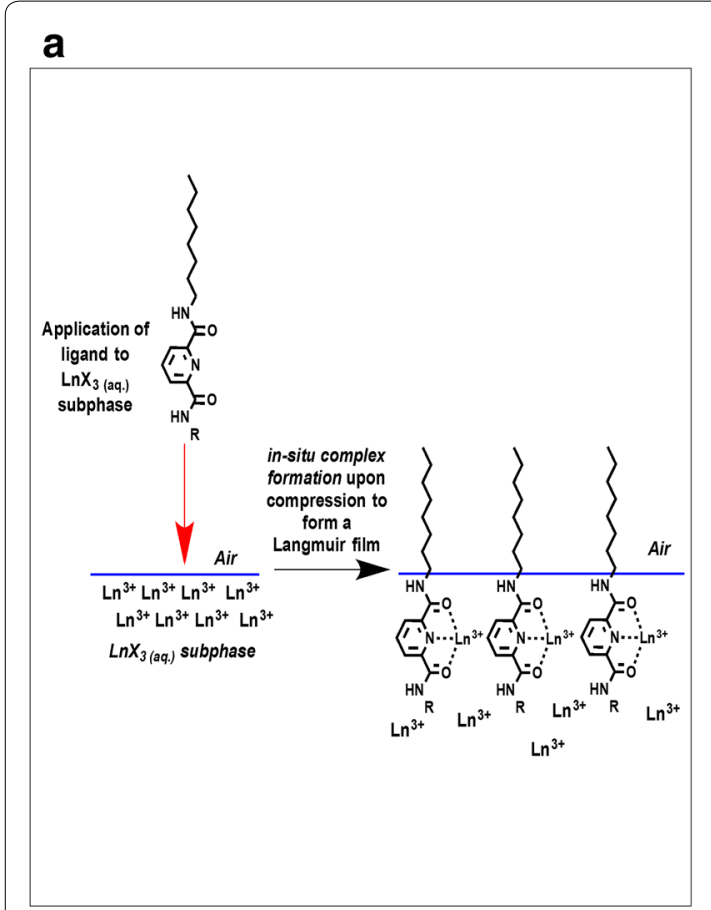

b

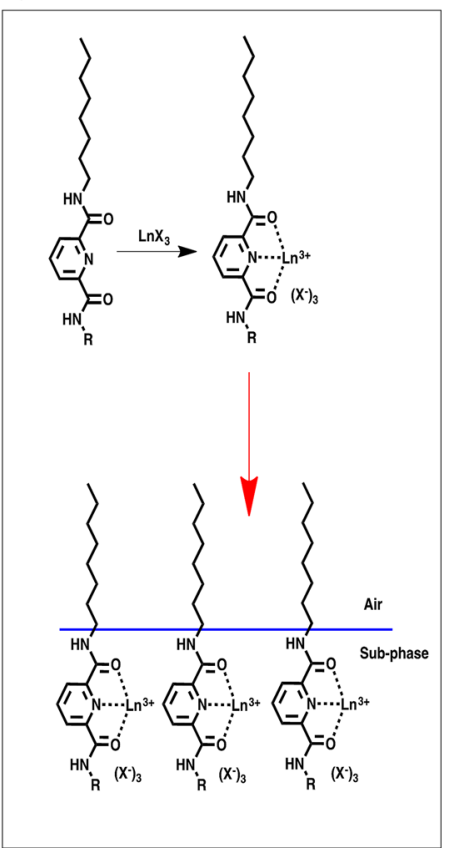

C

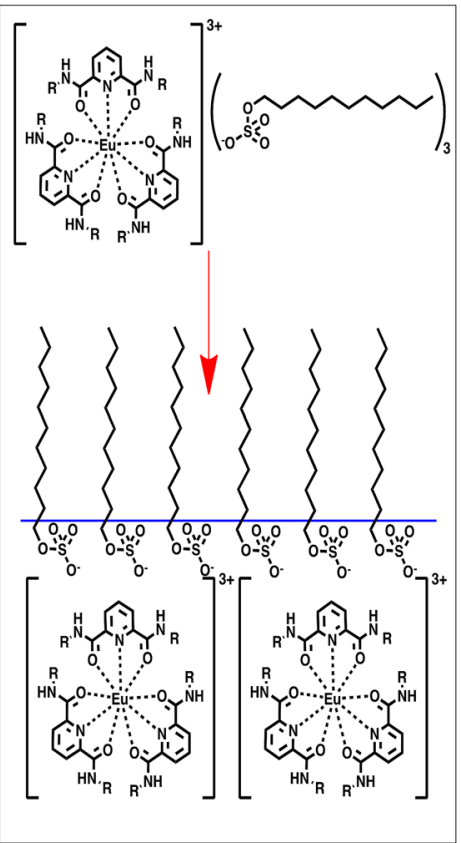

Fig. 2 Schematic showing the three methods to prepare Ln(III) amphiphiles. a In situ formation - a free ligand is applied to the surface of a $L n(I I)$ containing sub-phase. As the barriers are compressed the ligands coordinate to the $L n(I I I)$ in the sub-phase and form a complex. b Pre-formed complexes - an amphiphilic ligand is first complexed with Ln(III) and then the resulting amphiphilic complex is applied to the surface of the LB trough. c Ln(III) complexes with amphiphilic counter ions-in these systems the counter ion (anion or cation) has amphiphilic character and the ion-pair formed is applied to the surface of the LB trough

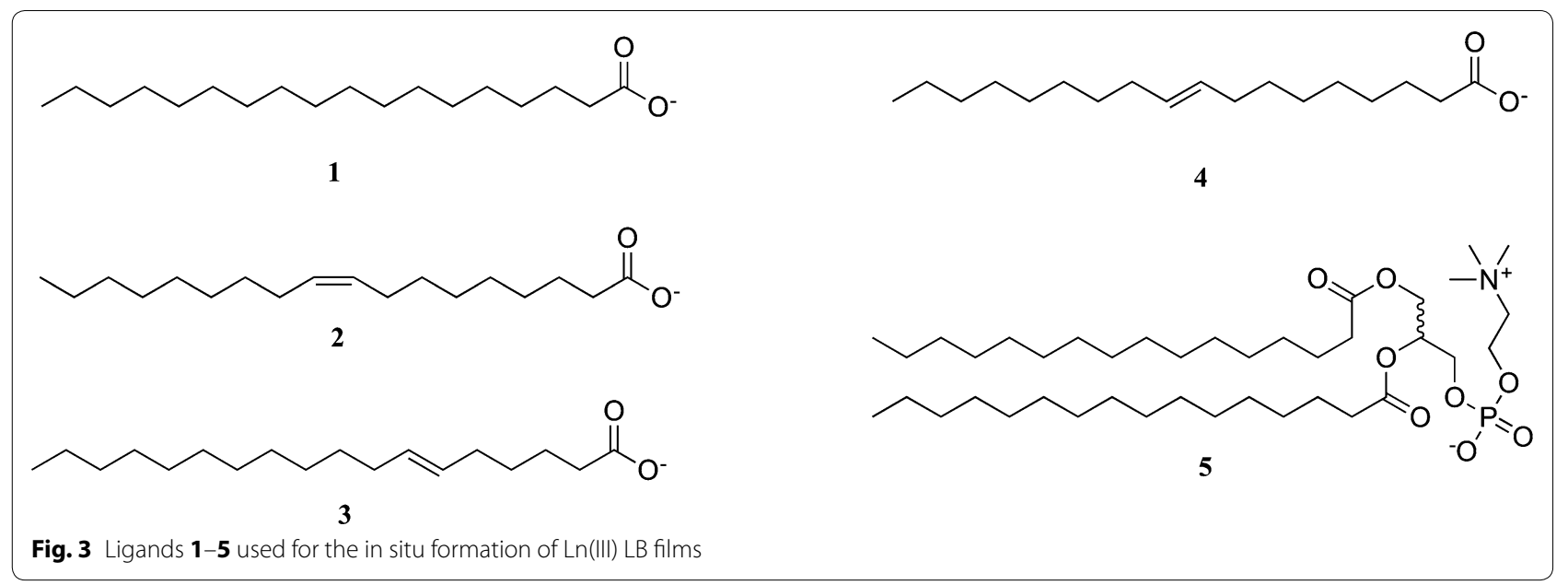

and $\mathrm{Tb}(\mathrm{III})$ took place in the solid LB films with high efficiency, and following direct comparisons between energy transfer in solution and in the film, they concluded that in both cases energy transfer occurred via similar mechanisms. $\mathrm{Xu}$ and co-workers prepared amphiphilic complexes of $\mathrm{Tb}(\mathrm{III}), \mathrm{Dy}(\mathrm{III})$ and $\mathrm{Eu}(\mathrm{III})$ using 10 (Fig. 5) [14]. Solutions of the three pre-formed lanthanide complexes, $\left[\operatorname{Ln}(\mathbf{1 0})_{2} \mathrm{NO}_{3}\right]$, were deposited onto pure water sub-phases and LB films prepared. Efficient emission from LB films of $\left[\mathrm{Tb}(\mathbf{1 0})_{2} \mathrm{NO}_{3}\right]$ and $\left[\mathrm{Dy}(\mathbf{1 0})_{2} \mathrm{NO}_{3}\right]$ were observed with characteristics similar to the bulk solids. However, in LB films of $\left[\mathrm{Eu}(\mathbf{1 0})_{2} \mathrm{NO}_{3}\right]$ the emission was much weaker, likely ascribed to the triplet state energy of $\mathbf{1 0}$ being less efficient at sensitising 


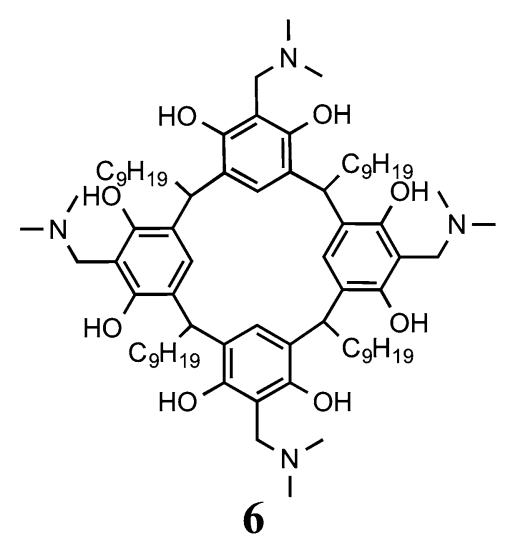<smiles>C#CC(C)(C)C(CCCC)c1cc(C)c(O)c(CN(C)C)c1O</smiles>

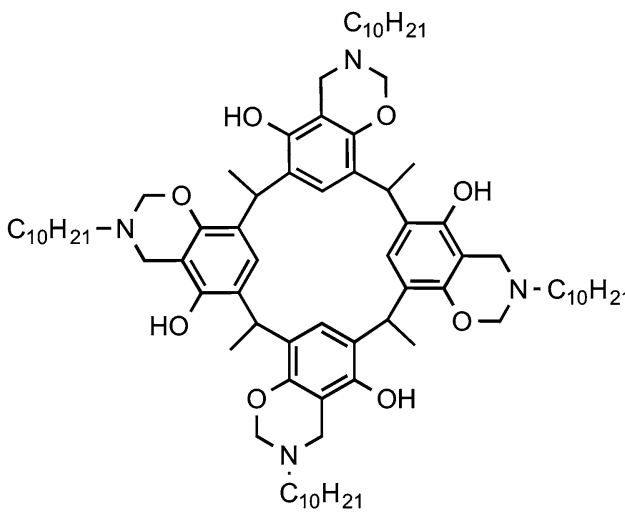<smiles>Cc1cc(C(C)C)c(O)c2c1OCN([14CH3])C2</smiles>

7

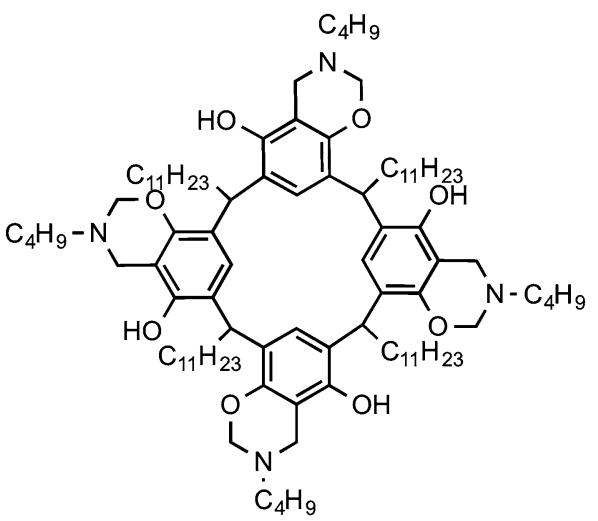<smiles>[CH]C(c1cc(C)c2c(c1O)CN([14CH3])CO2)C(C)(C)C#C</smiles>

8

Fig. 4 Calix[4]resorcinarene derivatives 6-8 investigated by Neveshkin et al

$\mathrm{Eu}$ (III) compared to $\mathrm{Tb}(\mathrm{III})$ and $\mathrm{Dy}(\mathrm{III})$. The same group also reported the in situ fabrication and subsequent emission properties of LB films of $\mathrm{Eu}(\mathrm{III})$ and Dy(III) complexes of 11 (Fig. 5) [15]. Serra and co-workers investigated the in situ formation of $\mathrm{Eu}(\mathrm{III})$ complexes of the amphiphilic $\beta$-diketonate ligand 12 (Fig. 5) [16]. The multi-layered (3 layers) LB film obtained displayed the characteristic emission associated with $\mathrm{Eu}(\mathrm{III})$ and was similar to solution and solid-state emission measurements of $\left[\mathrm{Eu}(\mathbf{1 2})_{6}\right]$. 


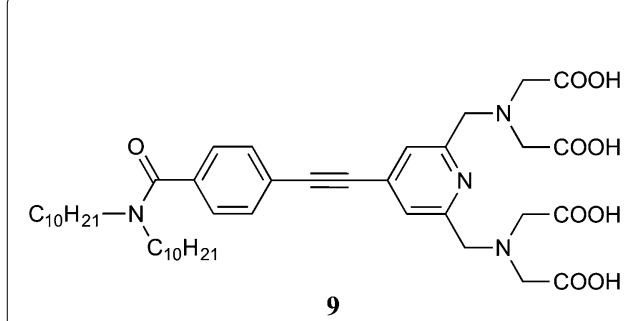

Fig. 5 Ligands $9-12$

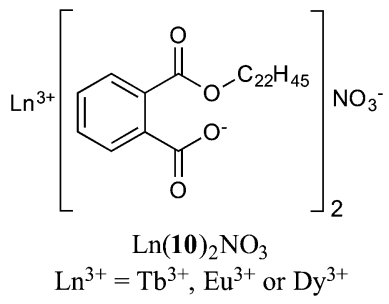

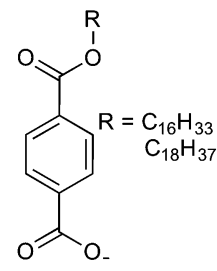

11

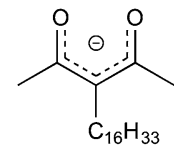

12
Whilst the above results suggest that LB film formation has little to no effect on the quantum yield or emission properties of the $\operatorname{Ln}(\mathrm{III})$ systems, Zaniquelli showed otherwise with investigations using in situ formed of multilayered $\mathrm{Tb}(\mathrm{III}$ ) films of $\mathbf{1 3}$ and $\mathbf{1 4}$ (Fig. 6) [17]. LB films of these systems displayed emission that was highly dependent on the number of layers deposited. In the $\mathbf{T b} \cdot \mathbf{1 3}$ film, a total of 6 layers were deposited but maximum luminescence was observed at 4 layers. Similarly for $\mathbf{T b} \cdot \mathbf{1 4}$ a total of 4 layers were deposited, but maximum emission was observed for 2 layers. The quenching of emission on additional layer deposition was ascribed to the inner filter effect [18]. Therefore, in this system it was not the film formation that resulted in quenching, but the successive deposition of films.

Wang and co-workers carried out an interesting study investigating the emission from films deposited at different surface pressures [19]. The pre-formed complex, $\left[\mathrm{Eu}(\mathrm{TTA})_{3}(\mathbf{1 5})\right]$ (TTA $=$ thenoyltrifluoroacetone, Fig. 7), formed stable Langmuir films on a pure water sub-phase. However, whilst the LB films transferred at lower pressure $\left(12 \mathrm{mN} \mathrm{m}^{-1}\right)$ displayed reasonable emission, the films transferred at higher pressure $\left(30 \mathrm{mN} \mathrm{m}^{-1}\right)$ resulted in significant quenching of emission. This observation was attributed to aggregation of luminophores within the LB film, showing that altering film formation parameters can dramatically influence the photophysical properties of the $\operatorname{Ln}($ III) amphiphiles. Such aggregation induced quenching appears highly ligand dependent as the same group also reported the synthesis of the phenanthroline based complex $\left[\mathrm{Eu}(\mathrm{TTA})_{3}(16)\right]$ (Fig. 7) [20]. In this case LB films formed at $30 \mathrm{mN} \mathrm{m}^{-1}$ gave multi-layer LB films that displayed strong emission, with no evidence of aggregation induced quenching. The examples discussed above emphasise that both ligand choice and film formation parameters can significantly affect the emission properties of the LB film, therefore multiple factors must be investigated/considered in ligand design.

Gunnlaugsson and co-workers demonstrated the power of rational ligand design when fabricating films for specific purposes [21-23]. In this study the first examples of circularly polarised luminescence (CPL) was reported from mono-layer LB films of the chiral complexes $\left[\operatorname{Eu}(\mathbf{1 7}(\mathbf{R}))_{3}\right]$ and $\left[\operatorname{Eu}(\mathbf{1 7}(\mathbf{S}))_{3}\right]$ (Fig. 8). The ligands were pre-designed to include a terdentate coordination pocket, a chiral sensitizing antenna for the $\mathrm{Eu}(\mathrm{III})$ ions, an aliphatic chain, and in addition allow facile formation of enantiomerically pure Eu(III) complexes. Upon transfer of the chiral pre-formed complexes to a quartz substrate, it was confirmed by circularly polarised luminescence spectroscopy that the LB mono-layer films gave rise to $\mathrm{Eu}(\mathrm{III})$ centred $\mathrm{CPL}$, i.e. chirality at the metal centre was maintained on deposition.

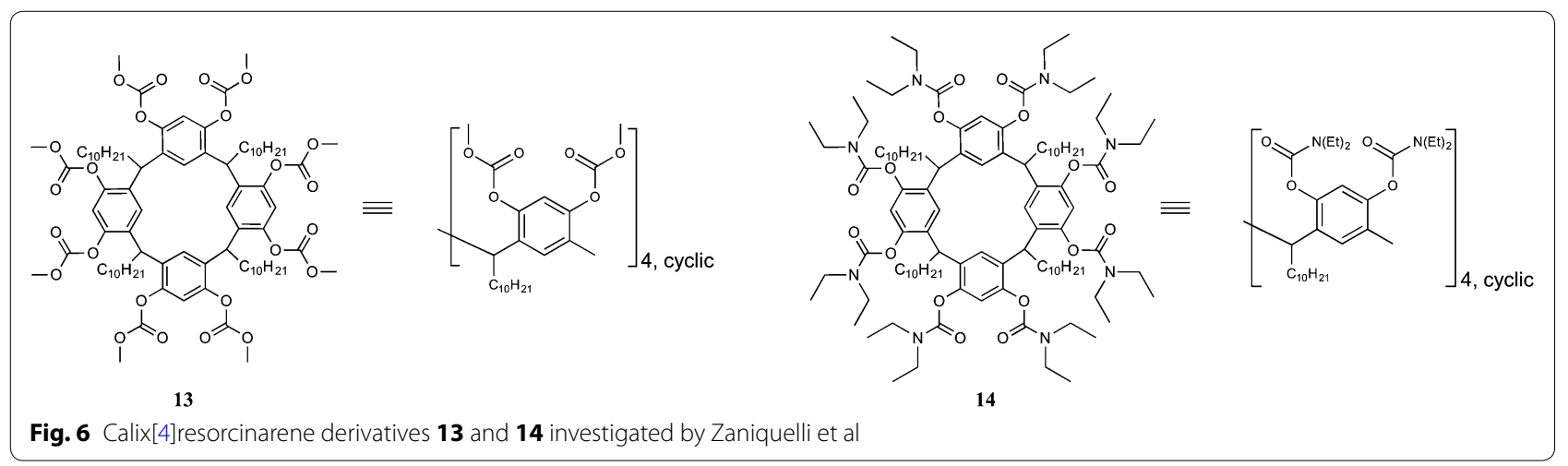



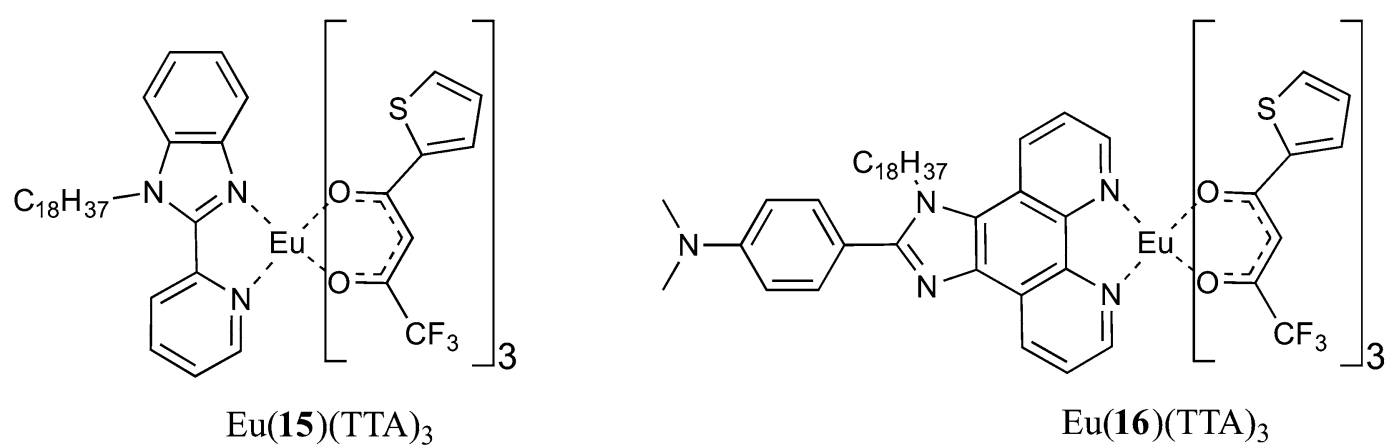

$\operatorname{Eu}(\mathbf{1 6})(\mathrm{TTA})_{3}$

Fig. 7 Pre-formed complexes of $\left[\mathrm{Eu}(\mathrm{TTA})_{3}(\mathbf{1 5})\right]$ and $\left[\mathrm{Eu}(\mathrm{TTA})_{3}(\mathbf{1 6})\right]$
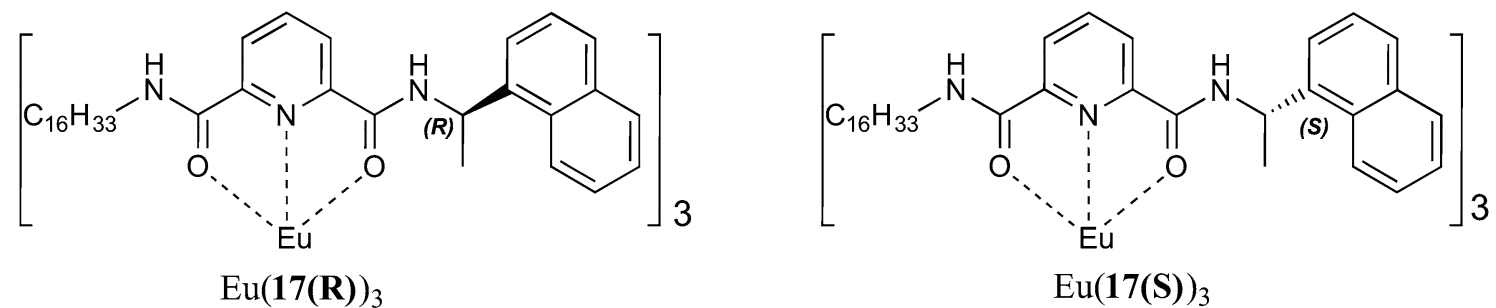

Fig. 8 Pre-formed chiral complexes $\left[\mathrm{Eu}(\mathbf{1 7 ( R )})_{3}\right]$ and $\left[\mathrm{Eu}\left(\mathbf{1 7}(\mathbf{S})_{3}\right]\right.$ developed by Gunnlaugsson et al

\section{Ln(III) Langmuir-Blodgett film sensors}

Whilst many potential applications of $\operatorname{Ln}(\mathrm{III})$ based LB films have been proposed, one application that has begun to be realised is the ability of LB films to act as sensors. The previous sections have shown that LB films of amphiphilic $\operatorname{Ln}(\mathrm{III})$ containing complexes can be obtained relatively readily and such films are reasonably homogenous in coverage with deposition that does not always adversely affect photophysical output (i.e. $\operatorname{Ln}(\mathrm{III})$ luminescence). In the following section we will explore the small number of examples that are present in the literature where these types of surfaces act as sensors.

Dutton and Conte reported LB films of octafunctionalised calix[4] resorcinarenes $\mathbf{1 3}$ and $\mathbf{1 4}$ (Fig. 6) which upon exposure to solutions of $\mathrm{TbCl}_{3}\left(2 \times 10^{-4} \mathrm{M}\right)$ abstract $\mathrm{Tb}$ (III) from solution, essentially acting as ion sequestration agents which respond to their local environment. This was an extremely important result as it showed that the formation of highly ordered LB films does not block the sensing component to modification from external perturbation, thus making LB films ideal for sensing [24]. However, no comment on film stability upon repeated dipping was given.

In a similar type of study, Novikova and co-workers used the X-ray standing wave (XSW) technique to analyse the structural localisation of trace amounts (solutions of $<10^{-7} \mathrm{M}$ ) of $\mathrm{Fe}, \mathrm{Zn}, \mathrm{Cu}$ and $\mathrm{Ca}$ ions incorporated (deliberately) into Langmuir-Blodgett films of $\left[\mathrm{Eu}(\mathbf{1 8})_{3}(\mathrm{Phen})\right]$ (Fig. 9) on a silicon substrate $[25,26]$. Whilst this study did not use emission as the output for sensing, it still reinforced the ability of LB films to respond to very low concentrations of analytes.

Serra and co-workers reported the ability of in situ prepared $\mathrm{Eu}(\mathrm{III})$ containing Langmuir-Blodgett films of $\mathbf{1 9}$ (Fig. 10) to respond to the organic compound, 4,4,4-trifluoro-1-phenyl-1,3-butanedione (BFA) [27]. When coordinated to $\mathrm{Eu}(\mathrm{III})$, this chelate is able to more effectively sensitise emission than 19 alone, therefore upon dipping the substrate coated in 19.Eu(III) into an aqueous solution of BFA there was a two-fold increase in emission intensity, indicating that BFA coordinated to the $\mathrm{Eu}(\mathrm{III})$ within the LB film. This study highlighted the dynamic nature of the $\mathrm{Eu}(\mathrm{III})$ ions in LB film, as they were able to change coordination sphere and hence act as sensors to BFA. It should be noted that no comment on the stability of the LB films to dipping in the solution of BFA was given.

In a more application-focused example, Caminati and Puggelli utilised $\mathrm{Eu}(\mathrm{III}) \mathrm{LB}$ films for the photophysical detection of trace amounts of the antibiotic tetracycline (TC) in solution [28]. Multilayered LB films consisting of $\mathrm{Eu}$ (III) cations and 20 (Fig. 11) on substrates were 


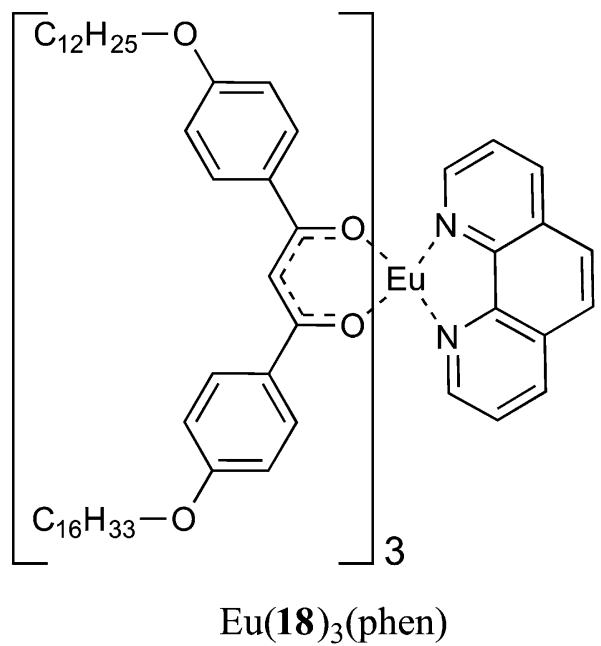

Fig. 9 Pre-formed complex $\left[\mathrm{Eu}(\mathbf{1 8})_{3}(\right.$ Phen) $]$ developed by Novikova and co-workers

dipped into solutions containing TC and then analysed using emission spectroscopy. No emission from $\mathrm{Eu}(\mathrm{III})$ was detected in the absence of TC, however, in the presence of TC (and with excitation at the absorption wavelength of TC) the characteristic sharp emission peaks of $\mathrm{Eu}(\mathrm{III})$ were observed. Using this technique, concentrations as low as $1 \times 10^{-8} \mathrm{M}$ of TC could be effectively detected. This study confirms the ability of
Ln(III) amphiphiles to act as highly sensitive luminescent sensors for trace amounts of biologically relevant analytes, but the stability of the sensing films was not explicitly discussed. However, it is noted that the LB films were exposed to $\mathrm{pH}=4$ conditions with no report of degradation.

\section{Conclusions and future perspective}

In this very brief mini-review, we have attempted to highlight the small number of LB films constructed from amphiphilic lanthanide complexes, in which at least one of the complexing ligands contains a covalently bonded amphiphilic moiety. Of the small family of $\operatorname{Ln}(\mathrm{III})$ amphiphilic systems made from both simple (e.g. 1-5, 19,20 ) and complex (e.g. 6-18) ligands the film forming abilities have been studied in detail. This has led to an understanding of the fundamental affect/s that the lanthanide cations have on the LB films and the effect that the LB film environment has on the properties (luminescence) of the $\operatorname{Ln}(\mathrm{III})$ cations. Despite an understanding of fundamental properties, the application of these systems for advanced materials (e.g. surface bound sensors, molecular logic gates/molecular electronics) is still in its infancy. Given the retention of $\operatorname{Ln}(\mathrm{III})$ emission and good film coverage afforded by the LB method combined with initial sensing studies, the future of amphiphilic Ln(III) systems immobilised as LB films will no doubt be rich.

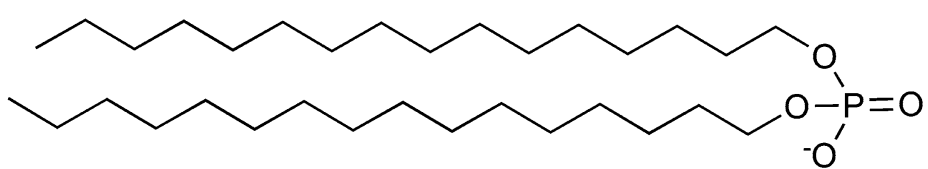

19<smiles>O=C(CC(=O)C(F)(F)F)c1ccccc1</smiles>

BFA

Fig. 10 Ligand 19 was used in conjunction with Eu(III) to detect BFA<smiles>CCCCCCCCCCCCCCCC(=O)OCC(COP(=O)([O-])[O-])OC(=O)CCCCCCCCCCCC</smiles>

20<smiles>CN(C)[C@H]1C(O)=C(C(N)=O)C(=O)[C@]2(O)C(O)=C3C(=O)c4c(O)cccc4[C@@](C)(O)[C@H]3C[C@H]12</smiles>

Tetracycline (TC)

Fig. 11 Ligand $\mathbf{2 0}$ used by Caminati and Puggelli to detect trace amounts of the antibiotic tetracycline (TC) 


\section{Abbreviations}

LB: Langmuir-Blodgett; BFA: 4,4,4-trifluoro-1-phenyl-1,3-butanedione; TTA: thenoyltrifluoroacetone; XSW: X-ray standing wave; TC: tetracycline; CPL: circularly polarised luminescence; NIR: near-infrared.

\section{Authors' contributions}

JAK conceived the idea for the review. Both authors read and approved the final manuscript.

\section{Acknowledgements}

The authors are grateful for the support of the Directed Assembly Grand Challenge Network. The authors also wish to thank Dr. Kelly Kilpin for helpful discussions and the University of Southampton for support of this work.

\section{Competing interests}

The authors declare that they have no competing interests.

\section{Funding}

The authors thank the Engineering and Physical Science Research Council for funding through grant references EP/N009185/1 and EP/K014382/1.

Received: 4 June 2016 Accepted: 23 November 2016

Published online: 28 November 2016

\section{References}

1. Cotton SA (2009) Scandium, yttrium and the lanthanides: applications. In: King RB, Crabtree RH, Lukehart CM, Atwood DA, Scott RA (eds) Encyclopedia of inorganic chemistry. Wiley, Chichester

2. Dossantos C, Harte A, Quinn S, Gunnlaugsson T (2008) Recent developments in the field of supramolecular lanthanide luminescent sensors and self-assemblies. Coord Chem Rev 252:2512-2527

3. Motson GR, Fleming JS, Brooker S (2004) Potential applications for the use of lanthanide complexes as luminescent biolabels. Adv Inorg Chem 55:361-432

4. Butler SJ, Parker D (2013) Anion binding in water at lanthanide centres: from structure and selectivity to signalling and sensing. Chem Soc Rev 42:1652-1666

5. Lehr J, Beer PD, Faulkner S, Davis JJ (2014) Exploiting lanthanide luminescence in supramolecular assemblies. Chem Commun 50:5678

6. Ariga K, Yamauchi Y, Mori T, Hill JP (2013) 25th anniversary article: what can be done with the Langmuir-Blodgett method? Recent developments and its critical role in materials science. Adv Mater 25:6477-6512

7. Adati RD, Pavinatto FJ, Monteiro JHSK, Davolos MR, Jafelicci M, Oliveira ON (2012) Synthesis of a functionalized europium complex and deposition of luminescent Langmuir-Blodgett (LB) films. New J Chem 36:1978

8. Huang CH, Wang KZ, Zhu XY, Wu NZ, Xu GX, Xu Y, Liu YQ, Zhu DB, Liu YW, Xue ZQ (1994) Optical and electrical properties of the Langmuir-Blodgett films prepared from a rare earth coordination compound. Solid State Commun 90:151-154

9. Rodriguez-Mendez ML, Antonio de Saja J (2009) Nanostructured thin films based on phthalocyanines: electrochromic displays and sensors. J Porphyr Phthalocyanines 13:606-615

10. Linden M, Rosenholm JB (1995) Influence of multivalent metal ions on the monolayer and multilayer properties of some unsaturated fatty acids. Langmuir 11:4499-4504

11. Chunbo Y, Xinmin L, Desheng D, Bin L, Hongjie Z, Zuhong L, Juzheng L, Jiazuan N (1996) Lanthanide ion induced formation of stripes domain structure in phospholipid Langmuir-Blodgett monolayer film observed by atomic force microscopy. Surf Sci 366:L729-L734
12. Neveshkin AA, Rusanova TY, Rumyantseva SS, Serdobintsev AA, Podkosov KV, Shtykov SN, Klimov BN, Gorin DA, Ryzhkina IS (2008) Effect of metal ions on the formation and properties of monolayers and nanosized Langmuir-Blodgett films based on diphilic aminomethylated calix[4] resorcinarenes. Russ J Phys Chem A 82:249-253

13. Lemmetyinen $\mathrm{H}$, Vuorimaa E, Jutila A, Mukkala VM, Takalo H, Kankare J (2000) A time-resolved study of the mechanism of the energy transfer from a ligand to the lanthanide(III) ion in solutions and solid films. Luminescence 15:341-350

14. Xu B, Yan B (2008) Fabrication and photophysical property of Tb(III), Dy(III) and $E$ u(III) complex LB films containing double functional ligand of long chain mono docosyl phthalate. Colloids Surf A Physicochem Eng Asp 329:7-11

15. Bing X, Bing Y (2009) Fabrication and properties of novel LangmuirBlodgett films with multifunctional molecular precursors of lanthanide complexes with long chain para-L-oxybenzoate $(\mathrm{L}=1$-palmitoyl, 1-stearoyl). J Optoelectron Adv Mater 11:169-174

16. Gomes LF, de Oliveira KT, Neri CR, de Sousa Filho PC, Dal Bianco MJ, Ramos AP, Zaniquelli MED, Serra OA (2008) Luminescent Langmuir-Blodgett film of a new amphiphilic Eu3 + $\beta$-diketonate. J Lumin 128:1339-1347

17. Santos J, Zaniquelli ME, Dutton P (2002) Calixresorcinarene complexation of rare earth ions in liquid monolayers and multilayer Langmuir-Blodgett films. Colloids Surf A Physicochem Eng Asp 198-200:605-611

18. Kubista M, Sjöback R, Eriksson S, Albinsson B (1994) Experimental correction for the inner-filter effect in fluorescence spectra. Analyst 119:417-419

19. Wang K, Gao L, Huang C (2003) Optical properties of the highly ordered Langmuir-Blodgett film of a strongly luminescent Eu(III) complex. J Photochem Photobiol A Chem 156:39-43

20. Bian Z, Wang K, Jin L, Huang C (2005) Syntheses of new amphiphilic europium(III) complexes for Langmuir-Blodgett films. Colloids Surf A Physicochem Eng Asp 257-258:67-70

21. Kitchen JA, Barry DE, Mercs L, Albrecht M, Peacock RD, Gunnlaugsson $\mathrm{T}$ (2012) Circularly polarized lanthanide luminescence from LangmuirBlodgett films formed from optically active and amphiphilic Eu(III)-based self-assembly complexes. Angew Chem Int Ed Engl 51:704-708

22. Barry DE, Kitchen JA, Albrecht M, Faulkner S, Gunnlaugsson T (2013) Near infrared (NIR) lanthanide emissive Langmuir-Blodgett monolayers formed using $\mathrm{Nd}$ (III) directed self-assembly synthesis of chiral amphiphilic ligands. Langmuir 29:11506-11515

23. Galanti A, Kotova O, Blasco S, Johnson CJ, Peacock RD, Mills S, Boland J J, Albrecht M, Gunnlaugsson T (2016) Exploring the effect of ligand structural isomerism in Langmuir-Blodgett films of chiral luminescent Eulll self-assemblies. Chem A Eur J 22:9709-9723

24. Dutton PJ, Conte L (1999) Terbium luminescence in Langmuir-Blodgett films of octafunctionalized calix[4]resorcinarenes. Langmuir 15:613-617

25. Novikova NN, Zheludeva SI, Stepina ND, Tolstikhina AL, Gaĭnutdinov RV, Erko Al, Haase W, Galyametdinov YG (2006) Structural localization of trace amounts of impurity ions in Langmuir-Blodgett films by the X-ray standing wave method. Crystallogr Rep 51:1041-1047

26. Novikova NN, Zheludeva SI, Stepina ND, Tolstikhina AL, Gaynutdinov RV, Haase W, Erko Al, Knyazev AA, Galyametdinov YG (2006) Arrangement of trace metal contaminations in thin films of liquid crystals studied by X-ray standing wave technique. Spectrochim Acta Part B At Spectrosc 61:1229-1235

27. Serra OA, Rosa ILV, Medeiros CL, Zaniquelli ME (1994) Luminescent properties of $\mathrm{Eu}^{3+} \beta$-diketonate complexes supported on Langmuir-Blodgett films. J Lumin 60-61:112-114

28. Caminati G, Puggelli M (2011) Europium in phospholipid nanoscaffolds for the photophysical detection of antibiotic traces in solution. In: Moreno LM (ed) Europium: compounds, production and applications. Nova Science Publishers Inc., New York, pp 203-228 